Kohl: a Journal for Body and Gender Research

Vol. 2, No. 2 (Winter 2016)

\title{
The Many Scenes of Queer Damascus
}

\author{
Mathew Gagné
}

\begin{abstract}
:
This paper examines the multiple queer spaces that constitute a queer socio-spatial landscape in Damascus, from a shopping street, to a small bar, cruising parks, public baths, and the Internet. Men deliberately cross the borders that differentiate, yet connect, these spaces, from the physical environment to personal and social histories, the codes and social networks embedded within these scenes. Based on an ethnography conducted between 2010 and 2011, this paper considers how movement among these spaces produces the collective makings of differentiated queer subjectivities. I focus on movement to explore the ways in which queer bodies and subjectivities take shape as effects of the relations between these bordering spaces while men pass through and inhabit them. There is no monolithic sexuality in Damascus, but many kinds that are bordered and porous, and come together in complex ways. Movement is a form of expression and of articulating claims to certain relations that make queerness intelligible in Damascus' urban space. This paper builds on literature in queer geography and ethnography about the social production of queer space to think about a framework of movement by which men narrate and express different forms of queer subjectivity.
\end{abstract}


Badik ${ }^{1}$ showed me Sha'llan street, but would not set foot onto it. A popular hangout spot for various groups of self-identified gay men, it was also the main street of his eponymous neighborhood. Instead, it was Ali who first brought me to the street, introducing me to his friends who gathered there on weekends, hanging out until the din of the street quiets, and then moved elsewhere or disbanded. Sha'llan is a boisterous social milieu of group arrangements and practices. Ali was also the first to introduce me to a nearby park known for men cruising. Men slowly walked the park's winding path while others sat on the bench, quietly chatting to strangers or watching those walking by. It was quieter, more surreptitious, and still with its own set of rules. Ali moved seamlessly between the spaces, exuding familiarity and comfort.

In this paper, I explore the spaces frequented by same-sex desiring men that constitute (before the Syrian civil war, from 2010-2011) a queer geography in Damascus: the streets, parks, bars, cafes and hammams where men congregate. ${ }^{2}$ These spaces border one another, not physically, but conceptually and socially. The borders are sets of abutting differences of queer bodies and practices that interconnect within a mapping of a queer landscape in Damascus.

Badik's disavowal and Ali's ease of movement raise questions about these queer spaces as encompassing forceful affective elements capable of instigating such different subjective positions. More than just spaces, I apply to term "scene" to think of these spaces as encompassing multiple kinds of social-cultural relations and meanings. To Will Straw (2004), a "scene designates particular clusters of social and cultural activity without specifying the nature of the boundaries which circumscribe them" (412). Their boundaries are drawn from their location, genre of cultural production, or the loosely defined shared social activity they encompass (Straw 2004). To Benedicto (2014), a scene is "a tangle of potential connections, an assemblage that comes together... [it is] at once part of city and apart from it" (4). Scenes have neither beginning nor end; even when they are empty of men for the night, they remain a way of mapping knowledge of the different and continuous kinds of queerness.

The concept of a scene opens space to think about interconnection and differentiation among them, much like the kind of suturing Salter (2012) speaks of to account for the porosity of borders. He abandons the line that differentiates borders in favour of a "suture" that links inside and outside, and looks to where and how mobile elements connect or clash. While each scene processes its own qualities and characters, they are not exclusive to a single scene, but are traversable queer actions and freely available expressions of queer formations. Combined, these scenes create a fuller map of the complexities of the socially meaningful terrain of queerness in Damascus. I look at how the bordered, yet interconnected, queer geography of these scenes create a matrix of spaces that map differentiated kinds of queer practices, bodies, and subjectivities.

Through a series of ethnographic moments, I aim to show the conditions of the various scenes and the relations between them. If the borders between the scenes suture spatialized queer formations, then

\footnotetext{
${ }^{1}$ All individuals are pseudonymous.

${ }^{2}$ Since the Syrian uprising, public queer spaces are more inaccessible and difficult to reach due to the checkpoints around the city. Also, most of my interlocutors have left Damascus for Europe and the Gulf.
} 
movements between them is an act of producing and expressing a queer self. I focus on movement between the borders of these spaces in order to explore how queer bodies and subjectivities take shape while passing through and inhabiting multiple kinds of queer space. What happens to queer bodies and subjectivities as they pass through open yet tense symbolic and material borders of different queer scenes?

Movement among these scenes crosses different geographies composed of complex sets of materiality, codes, and relations (Whatmore 2002; Ingold 2008). Impossible to separate these entanglements, we live and move within the dynamic relations among them. As Vannini (2015) writes: "Life is movement-geographic and existential kinesis. Movements of all kinds are profoundly social activities that are both perceptive of the world and generative and transformative of it" (3). If the life's elements exist within entangled conditions, it means that multiple conditions are already present, waiting to be stirred into formations through acts and movements. Such are the conditions of what anthropologist Kathleen Stewart (2008), calls "getting a life" as getting "yourself into something or getting yourself out of something you've gotten yourself into and on to the next thing" (72). For Stewart, objects, abstractions, categories, events, and bodies are some of life's elements entangled within scenes that come together, historically conditioned yet easily swayed and shifted. I follow her thoughts on "weak theory" as perception, wondering where objects and events might go as they encounter other objects. It is a relational theory that adds movement to life, where things are set in motion through encounter and movement, connection and disconnection. "It's a mode of production through which something that feels like something throws itself together. An opening onto a something, it maps a thicket of connections between vague yet forceful and affecting elements" (Stewart 2008: 72). I place my analysis in the center of this thought: men are producing the practices and subjectivities of queer life in Damascus via movement among bordered yet interconnected spatial-cultural queer scenes containing densely mapped social relations, conditions, and materialities.

\section{Queer Geographies and Damascus}

In Among Syrian Men, Gary MacDonald (1992), using the figure of the effeminate Zuzu walking the streets of Damascus in search of an active sex partner, locates queerness in the streets. ${ }^{3}$ He describes this queer world as full of loneliness, random sex, disappointments, resignations, isolation, being forever on the prowl in their "natural habitat: the street" (45). Both ethnocentric and orientalist, he characterizes this world as lacking a model of queer intimacy and domesticity that is in contrast to Western models of queer life.

While the street is a mutual setting of our queer mappings, I want to challenge his image of it as lonely, lacking, licentious, and lascivious. I suggest that the "street" (as a mapping of several public and semi-public locales outside the domestic sphere) is productive. Public streets, parks, and outdoor spaces have historically been important queer sites for sex and sociality both in the Middle East and the West (McGlotten 2005; McCormick 2006; Merabet 2014; Zaki 2014). Queer spaces contain various material and symbolic conditions

\footnotetext{
${ }^{3}$ While his account may be dated, as well as insufficiently theoretical or scholarly, I choose to use it because of the few accounts of everyday life among queer men in Damascus.
} 
shaping the (re)production of social identities and relations (Valentine 2002). Queer spaces challenge the norms of space by contesting dominant spatial relations, sometimes appropriating them for queer ends (Binnie 1997; Merabet 2014), akin to Munt's Lesbian Flâneur ${ }^{4}$ who seeks intelligibility from her spatial movements, a sort of sense making of "temporary, simultaneous, multiple identification mapped out in moments ..." (Munt 2002: 258) "A subculture made invisible by its parent culture logically resorts to space making in its collective imagination. Mobility within [queer space making] is essential, because motion continually stamps new ground with a symbol of ownership" (Munt 2002: 253). Queer spaces also contain (relative) freedom and visibility for sexual desires and performances that authenticate queer socialities and practices among a bound spatialization (Davies 2013; Sibalis 2004), as well as sex spaces that violate processes of governmentality that regulate sex via law, state policy, and the liberal order of life into different spheres (Bell \& Valentine 1996; Ingram et al. 1997). A lacuna of the literature is its primary focus on conceptualization of space as singular types - bars, clubs, parks, public washrooms, neighborhoods - rather than bordered and differentiated, yet interconnected queer topographies.

The spatial paradigms emerging from this literature do not easily fit unto Damascus given the asymmetries of Western historical movements of sexual liberation, gay pride, visibility, and the struggles for political capacity to claim spaces that are available to be claimed (McCormick 2006; Georgis 2013; Merabet 2014). Queer space in the Middle East is produced in relation to different sets of identity politics that claim spaces, like gendered and sectarian politics (Merabet 2014; Zaki 2014).

There are few ethnographic works on queer space in the Middle East. From Cairo, Zaki (2014) has written about queer scenes as the socio-spatial sites of queerness congealing into a landscape of the city that men acknowledged as sites of fluid and fluctuating alternative sociality. From Beirut, a nearby city with a shared history to Damascus, Merabet (2014) theorizes the "homosexual sphere" as an amorphous social sphere constituted by manners of dress, style, tastes, performances of masculinity, and class consumption in Beirut. "Zones of encounters" are those spaces in and around Beirut where queer men meet, namely bars and cafes (some of which have closed due to state intervention) as well as public cruising zones like the concrete Corniche along the Mediterranean Sea (Merabet 2014). The social production of these spaces are intersected by politics of class access, gender performances of masculinity, and sectarian histories that shift and move. In producing queer space through the "performative bodily practices of gendering for young Lebanese men as they formulate their sense of what it means to 'exist' among numerous physical and mental maps" (Merabet 2014: 3), men contest, appropriate, or transgress the coded fixities and spatial meanings they encounter. Sometimes using them taken beyond their intended purpose. Queer men passing through and inhabiting these various spaces means navigating those conditions already there.

Queer spaces are still part of sectarian, religious, and social identities that more widely mark social space, creating dynamics whereby multiple relations make stronger claims to public places (Salamandra 2004; Seidman 2012; Merabet 2014). Crossing queer spaces also means crossing various social relations that

\footnotetext{
${ }^{4}$ In the context of my paper, the lesbian flâneur stands apart as a queer figure because she is also transgressing the masculine imperative of the street, which the men in Damascus can pass through.
} 
shape the queer practices coming into formation within. Crossing these borders leads to complex formations of queer space that sometime reproduce normative spatio-social codes, appropriate, and/or transgress them.

\section{Queerness in Damascus}

In the Middle East, NGOs and transnational activism have lent queer sexuality a politics of visibility based on liberal discourses of identity, rights, and tolerance (Moussawi 2015), which has professionalized activism through strategy, reporting measurements, funding, and institutional hierarchy (Markowitz \& Tice 2002; Wehbi \& Lahib 2007; Butterfield 2016). Paul Amar (2013) contends that, in Cairo, discourse on queer sexualities results from anxieties of fast-paced globalization and the reconfiguration of security apparatuses, whereby NGOs are mobilized within "human-security governance" (7). For Amar, it was the security archipelago that "had acted, since at least the 1980s, to generate these 'globalizing sexuality' subjects as their other" (p.75, as quoted in Qubaia, forthcoming).

The major preoccupation of the field in recent years has been Joseph Massad's (2007) critique of Western sexual hegemony having colonized Middle Eastern queer subjectivities and for creating Western derived sexual identities where there were none. Others (Georgis 2013; Mourad 2013; Hamdan 2015), while acknowledging the problem of western hegemony, refute his claims on the grounds of more complicated processes of adoption and translation. To Dina Georgis (2013), Massad's claims search for an authentic precolonial sexual epistemological system, overlooking complex relations between forces of localization, local socio-political structures, global flows, and the interplay between tradition, authenticity, and modernity. Georgis (2013) contends that colonial regulations of sexuality created the post-colonial affect of shame of non-normative sexuality, which greatly shapes queer Arab epistemologies. This colonial shame is in tension with contemporary promotions of gay pride by the "global gay" (Altman 1996), preventing non-western queers from dealing with vestiges of colonial sexual shame.

Sexualities travel, often becoming insinuated into localized and historical fields of formation at different periods. Readings of texts (literary, political, religious) from both per-colonial and post-colonial eras illustrate the legal, discursive, and authoritative mechanisms that shaped sexuality (Bouhdiba 2001; El-Rouayheb 2005; Habib 2007; Massad 2007). Theological traditions have regulated non-normative sexual practices from linguistic taxonomies of sexual acts (such as luti, meaning receiver of anal penetration), classifications of types of desire as passionate infatuation/sexual lust, and hierarchical distinctions among sexual acts (ElRouayheb 2005). Habib (2007) argues that acknowledgement of female homosexuality within medieval texts has historically been present, but that changing notions of sexuality have altered and shaped the contemporary terms of discussion. Work on queer formations in post-colonial Arab literature have attempted to reconsider the tension between "premodern Middle Easter versus modern Western-oriented division" (AlSamman \& El-Ariss 2013: 205). More recently, activists created new terminologies by which to refer to nonnormative sexualities that are neither culled from the past and taken out of historical epistemologies, nor indexed to a Western sexual epistemology: Mithli and Mithliyya describe homosexuality, and is gaining traction with the Lebanese media, at least. Some activists have reclaimed the term shadh (deviant, or 
pervert), as well as transliterated 'queer' into Arabic as a political signifier (Mourad 2013). The binaristic preoccupation of an area studies paradigm that is simultaneously about the Middle East and queerness tends to create objects and lines that overlook the movements between the historical and abstract of scholarly materials. There are contemporary works examining the traces of queerness historically, taking not rupture, but movement among texts - particularly the dynamics of a queer materials and examples that are in flux to account for the shifting of queer sexualities over presence and absence.

Recent literature examines the contemporary conditions shaping queer sexuality by tracing the emergence of different discourses and conditions through a history that disrupts the colonial encounter as primary, to look at other moments and conditions (Babayan \& Najmabadi 2008; Habib 2009). Some scholars trace threads of queer affects and desires between this distinction, along with the classical and modern, literature and politics. Such readings reveal a historical, multi-layered emergence of queerness in the intellectual history of the region. They use affect as a means of tracing these formations through shame, lust, desire, silence, madness, terror, empathy, and so on, "as transformative sites for the emergence of queer identifications" in the region (Al-Samman \& El-Ariss 2013: 206). Tracing the threads of different affects - their emergence and their role in generating queer forms - enables these works to reveal particular regional social, historical, and political conditions shaping queer sexualities.

In Syria, queer sexualities are criminalized. Article 520 of the Syrian penal code criminalizes illicit sex deemed against nature, making anal intercourse between men punishable with up to 3-years imprisonment. Literature shows that states implement various polices and mechanism in the production of gendered and sexual citizens (Joseph 2010; Maktabi 2010). State instruments and omnipresent secret police force people to act in relative silence, out of fear of being caught. There were arrests of men caught having sex, but, unlike in Egypt and Lebanon, raids and mass arrests were uncommon. Socio-economic factors, increased mobility, tourism, and media flows brought in new influences and queer culture leading to new queer claims and differences between queer men.

My ethnographic eye enumerated five queer scenes. ${ }^{5}$ The "Sha'llan street scene" is associated with a main shopping district near the center of Damascus. Groups of men inhabit the street, associating themselves to class-based consumption and gay identities. The "park scene" refers to the public parks where men cruise in relative darkness, primarily socializing and flirting with men and for sex, if the circumstances line up. A friend in Damascus once said: "where there is a public park there are men cruising," but the most known - and the subject of this discussion - was Monchieh Park, located next to the Four Seasons Hotel. Two scenes of similar ilk are the "bar scene" and "hammam scene." While not exclusively queer, these are private enterprises known as places of queer sociality and sex. Finally, there is the "Internet scene" of gay dating websites, specifically manjam.com and gayromeo.com. This scene includes men from all scenes, but also absorbs men avoiding other scenes. While the places queer men occupied were multiply located all over the

\footnotetext{
5 In naming these spaces as scenes, I am imbuing them with certain socio-relations meanings and spatio-temporal correlates for the kinds of practices and performances that occur within and are reflected in the ways that men perceived, talked about, and moved among them.
} 
city (private homes, other parks, and cafés and restaurants), I name these spaces because they were popular locations hosting distinct queer practices and performances. They were shown to me as places where men congregate in certain ways, thereby passing on knowledge of these spaces as queer.

The mere existence of these queer scenes is not the remarkable notation of this paper. It is rather the emergent effervescence of queerness at the surface of urban spaces. This effervescence, which imbues spaces with collective queer socialities, marks sub-cultural formations in a place often deemed to have none. While the term "queer" is useful to connote a range of same-sex sexual desires within Damascus, and while not privileging one mode of non-normative sexual practice, I also use it for its political meanings. According to Butler (1993), queer is also "a site of collective contestation, the point of departure for a set of historical reflections and futural imaginings ... [that] will have to remain ... never fully owned, but always and only redeployed, twisted, queered from a prior usage and in the direction of urgent and expanding political purposes" (228).

\section{Walking as Method and Positionality}

This paper is based on a period I spent studying Arabic in Damascus. ${ }^{6}$ I arrived in the city-my second time following a tourist stint-with only the results of a cursory internet search about queer spaces. I learnt of these scenes by walking around, past, and through them with new friends. In addition to participant observation, I engaged in a methodological practice of walking. De Certeau (1984) argues that the movement of walking makes legible a meaningful text made from the possibilities, codes, networks, connections, paths, place names, and streets taken and not taken. Walking stirs up the kinds of conditions and elements Stewart (2008) describes as always present and available to assemble into a scene, appropriating and giving form to spatial signifiers in relation to other things happening. This can, in De Certeau's (1984) words, create a poetic geography of new open spaces from movements via other routes. Spaces within this poetic geography can be formed differently, yet still subjected to other forces that arrange and classify socio-spatial relations. They are made from the interplay of territorialized and emerging elements.

I share this method with Merabet (2014), who says that walking employs all the senses to perceive the capacity for social spaces "to orchestrate the desire of those who inhabit them" via low-laying events, encounters, and symbols (Merabet 2014: 210). In the subtle and unstable elements of queer spaces, walking is not only a mode of mapping the relations of the scenes, but of negotiating access and orientation within (Whatmore 2002). Walking allowed me to observe ordinary moments as significant, as those instances when something different might occur or something queer might form and stick, no matter how slight.

As a queer man, I developed my own trajectories around these spaces, among the social groups, benches, walkways, tables, and other elements found in these queer spaces. My own movement with these scenes must account for my positionality in how I occupied spaces. My experiences with these scenes, including my

\footnotetext{
${ }^{6} \mathrm{I}$ undertook exploratory fieldwork and language training in preparation for further graduate studies.
} 
moments and relationships with interlocutors shapes my framing (Pace 2012). I make myself present in the narratives but I engage with informants beyond the self (Pace 2012). According to Madison (2005), critical ethnography is "a meeting of multiple sides in an encounter with and among the Other(s), one in which there is negotiation and dialogue toward substantial and viable meanings that make a difference in the Other's world" (9).

As a narrator of these scenes, I describe a general ethnographic image culled from a period of participant observation, punctuated by moments with interlocutors. Despite the passing of time, these scenes are replayed, occupied by a range of individuals and collective moments that are meaningful to the personal narratives of interlocutors. Such events are situated within a particular time and place, among different social actors with varying lives. Such methodology encompasses an ethnographic look at socio-spatial productions, from knowledge situated in a given spatial-temporal context, to the fluidity of space and subjectivity (Haraway 1988).

\section{Differentiating Scene Borders: Badik's Disavowal}

Badik and Ali were the first to introduce me to the Sha'llan scene, but differently. Badik emphasized the boundaries of the scenes, whereas Ali showed me their porosity. I met both through the Internet scene specifically gayromeo.com 7 - and both offered to tour me around. While walking through Badik's neighborhood (which later became my own), he explains why he avoids Sha'llan street: "on weekends, there are groups of guys hanging out on the street. I don't because they are too obvious, and since this is where I live, I don't want to be connected to them." He prefers to keep his queer life to gay dating websites where his connections are more private, and he can pursue his preference for connecting with foreign men in the city. He had a group of gay friends, all of whom he met online. The group became a lifeline for him to engage in various forms of queer socialities outside his other social networks. They avoided Sha'llan street for the forms of visibility and queerness it contains. Men were noticeable, and boisterously flaunted themselves, not to forget the gossip and cattiness that was characteristic of the scene. ${ }^{8}$

By not accompanying me into the space, he was performing a boundary-making act between the scenes, but also between himself and these scenes. The boundary he made was partially based on physical territory his queer life took him to spaces other than sha'llan - as well as the social and symbolic materials these scenes contain. The border between Sha'llan and the Internet scene is made by mobile sets of codes and meanings, or bodily actions and desires (Vaughan-Williams \& Parker 2009) that he articulated and made meaningful by both his characterization of the street and his disavowal of it. Badik was not only concerned

\footnotetext{
7 The site was primarily popular among European men and locals who wanted to meet foreigners. Manjam.com was more popular among local men. There were few users on this site, but it was productive in finding people to help with settling into the city.

${ }^{8}$ At one point, an anonymous profile appeared on Manjam.com gossiping about men in the Sha'llan scene. Each week, the owner would contact a local user via the site, conduct an interview over MSN messenger and then post the new gossip about the scene in the profile.
} 
with being visibly queer on the street, but with being attached to, and affected by, the kinds of queer sociality within Sha'llan. He didn't see himself as that kind of queer. As Christopher Pullen (2012) notes, passing borders means cultivating "equivalence and recognizability in forming or matching identity ideals" (28). Crossing into Sha'llan meant that Badik would adopt and become recognizable by the forms within. His disavowal is equally a claim to a queer subjecthood and to queer practices that are different from Sha'llan.

The Internet scene allows for increased means of connecting outside of these scenes: in private homes, Internet cafés, and commercial businesses. ${ }^{9}$ Men connect quickly and more widely with others through their user profiles. The internet scene was a complex space enveloping elements and individuals from all scenes. Yet, it was also distinct for including those who rejected the other scenes in search of a western-derived model of queer intimacy that had become tensely insinuated into the local, "regulated by... local notions and practices of embodiment and sociality" (Povinelli \& Chauncey, 1999: 442). Salim, for instance, was professionally employed, educated in Europe, and from a well-off family. We met in a European style café in one of the upper-class areas of Damascus. He informed me of his disavowal of most scenes. He tells me: "through the Internet, I can meet like-minded guys, and maybe find something more meaningful." He was looking for a stable relationship with a guy, something resembling heteronormative model of respectable coupledom as opposed to casual, especially public, sex. Plus, through the internet, he could move anonymously, and control his visibility and interactions. His disavowal of other scenes was part of a claim he made about his queer selfhood for a privatization of sexuality and a model of intimate life based on coupledom and private living that was in contrast to the street as the location of queerness.

Such claims are more than forms of mimesis, but of what Boellstroff (2005) calls "dubbing culture," where "elements are held together in productive tension without the expectation that they will resolve into one" (5). The result of this tension has been the emergence and differentiation of these scene from the asymmetrical and tense insinuation of different cultural forms in different ways. Both men claimed an affective position towards one scene over another, expressing a discomfort or distaste for one, and a preference of others. Affective emergences are experienced in relation to environmental factors (Navaro-Yashin 2012) challenging the subjective-objective divide by arguing that there are affective forces outside of the hermeneutics of the individual (Brennan 2004). In other words, their sense of queer self is tied to the force of the complexity of the environment, and their interaction to the density of interconnected elements.

\section{Moving Among Scenes: Ali and Abd's Different Takes on the Same Scenes}

Ali, a young man from the Druze area of Damascus, brought me to Sha'llan street and introduced me to his friends (all in their youth, and from different religious and class backgrounds). They bonded through their symbolic matrilineal kinship structure focused on the figure of the mother as the individual who introduced

\footnotetext{
9 This was prior to the arrival of geo-locations apps in Damascus. The state blocked the websites, but men would use an HTTP Proxy to bypass restrictions. Men, when congregating close to one another, would communicate wirelessly by sending text messages and exchanging files over Bluetooth.
} 
each one to the social group. The arrangement defined groups within the larger network in Sha'llan. Their sisters were those men who their mother had brought into the group, and their grandmother was the person who introduced their mother. The structure defined their social relationship to one another and their main social group, providing an affective anchor for their social lives within the scene. I got to know the group over the months (many of whom are now in various European cities). The street was not our only territory: traditional cafés, parks, the old city, driving around, were the space where this scene congregated.

Upon entering the bustling shopping street, Ali pointed out the corners and small parks along its perimeter where groups of men hang out. On any given weekend night, crews of young men stroll up and down the street, laughing, jostling, and touching, while socializing with other groups. Their movements through the space play with the punitively heteronormative gazes of those around them and violate heteronormative embodiments by walking with a hip-swaying swagger, ostentatious flirting, or using Arabic female pronouns and female nicknames (their namesakes often being their favorite female Arab pop star).

Such performances claim a degree of public visibility, garnering attention for their queered movements amidst the heteronormative socialities happening in the street. They appropriated and contested the heteronormative codes that inhabited the street. They tried to challenge and push these codes with their bodies, gestures, and boisterous talk. When performances exceed, such as too physical or too loud, someone interjects with saabo! saabo!, an imperative calling for the transgressor to "act straight" lest they attract punitive attention, the word being part of an argot among the Sha'llan scene.

Police and state authorities directly regulated the space, watching over the commercial activities. The gaze of the state observed the men, creating a tension of how far their transgressions of heteronormative space could go. Sha'llan scene was a space of appropriating and contesting heteronormative codes while passing through the street. Men often reveled in pushing the boundaries of the space, while pulling back if it became too risky. These actions were part of a process of developing the limits of acceptable public behaviors and forms of queerness. ${ }^{10}$ This is an act of testing how far queer acts might push of transgress the norms of heteronormative space, or of contesting them by eschewing identities and practice recognizable within heteronormative spatial relations that one might otherwise do while passing through new borders (Pullen 2012).

On the same night that Ali brought me to Sha'llan, he also took me for a walk through the cruising park five minutes from Sha'llan. The 'park scene' consists of two primped parks facing a main thoroughfare, and separated by a rising block-like hotel and commercial complex. The park features a winding pathway, with benches placed along it. Ali was not averse to entering the park, unlike those in his Sha'llan network who associated the park with a type of man just seeking sex and who would not embody the kinds of queer

\footnotetext{
10 There is a history of state oppression, violence, and incarceration among queer folks. Stories include soldiers being sentenced to prison after getting caught having sex while on duty, or those men arrested after a gay party was raided in a chalet just outside the city. Sometimes, incidents are unreported and used to blackmail those involved in the sexual act.
} 
representations and practices they do. We only passed through as an introduction. It wasn't until later, after meeting Abd, that I would know the park better.

I met Abd soon after, and we made exploring the other scenes our joint goal. Having only moved from the Arabian Gulf to Damascus with his family a few years before, he was keen to explore. Using mostly the Internet scene to arrange his queer intimate life, he abhorred the Sha'llan scene for its shallowness, superficiality, and emotional drama. He often referred to the men in Sha'llan as the VIPs, deemed highly desirable by their conventionally attractive faces and muscled bodies. Friendships in Sha'llan, he said, were not always disingenuous but were formed for a more superficial purpose: that of knowing primped and muscled men. He had a tense relationship with Sha'llan, but willingly moved into scenes others would not.

Abd and I frequented the park on any given evening. On one occasion, we struck up a conversation with a lone man who had been observing us. Middle aged, married with children, living in the outskirts, he mentioned that he infrequently came to the park for sexual gratification in the restroom. ${ }^{11}$ He gave us a brief introduction to the park: men stroll the park's spiral walkway glancing furtively or ostentatiously at others. A bit of eye contact is taken as an invitation to sit and chat amidst the circuits of walking and sitting. The man mentions that those sitting in the better-lit places are more conventionally desirable than those in darker spaces (although it is often a matter of who succeeds in getting these spots). The park's caretaker - perched atop a slope on the backside of the park - allows cruising with one rule: no touching in the open. Instead, men sometimes surreptitiously slip into the restroom for sexual delights. Men are furtive in their park affairs, often denying ever participating, or blocking recognition of acquaintances from another scene while ambling in the park. Occasionally, one develops social connections with other regulars, yet, unlike in Sha'llan, these did not form into networks that united men into social groups.

In the relative silence of the park, visibility and performance of queerness blends into its landscape. Bodily movement is slow and quiet, done for the purpose of being visible to others while not visible to all (such as the occasional soldier or city dweller who would wander through from the busy bus stop or military housing abutting the park). Desire is surreptitiously communicated by glances and small gestures of head nods, eye movements, sitting, and walking. Here, the queer body is marked by slow, gentle, and slight movements that indicate sexual interest. The kinds of boisterous bodily gestures and performances of the Sha'llan scene would be improper here, too ostentatious for the kind or queer practices the park creates and regulates.

In addition to the park, Abd and I also frequented a small bar in central Damascus where men sat, drank, watched TV, flirted, and engaged in sexual innuendo as looks and head-nods from across tables. Like the park, it is quiet and unassuming. From the second floor, the bar overlooks a busy business district meters from Souk Hamadieh, a main entrance to the Old City. The décor is 70's style with tabletops covered in dark red table covers, vinyl upholstered chairs, and shiny tiled flooring. The bar's large flat-screen television usually shows Arabic music videos or football matches. It serves cheap beer and whiskey, a rarity outside the Christian quarters of Old Damascus. Between conversing, drinking, and watching television, men glance

\footnotetext{
${ }^{11}$ Men across queer scenes often reside with their families and cannot host others for sex.
} 
around gauging social or sexual interest from the gazes of others. Occasionally, glances and flirtations across tables become head-nods indicating desire to meet in the bathroom. On one particular night, Abd was flirting with another patron through furtive glances across the room. After a few glances to establish interest, the other man nodded towards the washroom, a signal for Abd to follow him. A few minutes later they both emerged, and Abd said they looked at/showed each other's genitalia while at the urinal. Abd relished the experience, possibly as an adventure in an act he was not accustomed to performing: random sexual flirtations within semi-private spaces. It was a moment of experiencing queer sexual desires without him having to make claims to complex associations of sexual subjectivity alongside practices, meanings, and socialities within the scenes, or the need to claim visibility.

Abd was more comfortable sitting on the bench, chatting and flirting with one of the regulars. He was oriented towards spaces of surreptitious movements, desire, and sex; they served the kind of queer life he wanted. In exploring forms of sex and sociality within these scenes, his queer subjectivity eludes the types of identitarian containments of queer space and its relationship between sexual expression and subjectivity. His queer subjectivity was constructed in the acts and movements around queer spaces and of choosing to sit on a park bench or a table at the bar over ingratiating himself within the dense, judgmental networks of Sha'llan.

\section{Sex, Scene Borders, and Modernity}

Like the park and bar, the hammam was also known as a space of movement, looking, gazing, touching, sex. Men wander the rooms dressed in towels, gazing at others, reading sexual interest and consuming bodies. It is the salacious spectacle of a rawer sexuality that ignites one's queer lust, in spite of whether sexual encounters actually happen. In contrast to Sha'llan's ostentation among public space, the park, bar, and hammam scenes engage in a manner of performing queerness as surreptitious glances, stares, head-nodes, and encounters. Sex in the park, bar, and hammam scenes either happens within the semi-clandestine areas of those spaces, or privately in hotels, family homes, or the homes of friends living alone. For men in the Sha'llan scene, cruising for sex is primarily conducted through casual meetings with others from different social networks or via the Internet scene.

Scenes are marked by a divisive politics of sex. The Sha'llan and Internet scenes generally regard the park, bar, and hammam scenes as sites of sexual repression and backwardness, full of "un-modern" men: sexually repressed, lower-class, lacking access to circuits of culture and capital. In contrast, men in the park, bar, and hammam scenes were reticent to shift their queer lives towards the social networks of Sha'llan for the types of performances that mark a queer visibility in that space, and the dense social networks they entail. Tension between proper and improper forms of sexual performance are expressed in the ways men use the Arabic term sharmūtah (technically meaning female prostitute) as an insult (sometimes maliciously or as friendly ribbing) and commentary on one's sexual comportment. Sharmūtah in this context refers to the kind of tobji (derogatory for gay) who has sex with men then leaves without emotion, passion, or a sense of connection to queer others. Here, language extends into a politics of sex, respectability, and visibility to mark a boundary between individual and collective relations. 
Forms of sex and sexuality are associated with globally circulating queer cultural products, and models of sex and intimacy mark a border in Damascus between more progressive, western models of queerness and those more "traditional" that emphasize heterosexual family, religious identities, and the impersonality of queer sex. Social relations centre on the heteronormative family model as source of social and economic support, thus heternormativity must remain intact (Georgis 2013). As McCormick (2006) demonstrates of Lebanese gay men, these familial relations encourage men to live their homosexuality in relative secret not to risk losing the economic support typically provided by the family. This binary has been used to structure relations between these various scenes, to characterize some as more or less desirable depending on the kind of queerness one wants to lead.

Scene tensions were connected to the kinds of class distinctions that emerged from the economic and spatial transformations in Damascus in the 1990s and early 2000s. During this period, state policies controlling the incoming flows of global media and capital were slightly relaxed (to the bittersweet disappointment of Syrians hopeful for electoral and political party law reforms to open opposition politics), paving the way for the construction of restaurants, hotels, global clothiers, and leisure places. During this period, new forms of public culture and patterns of consumption, tastes, and attitudes shaped urban-consumer social contrasts that distinguished between elite and non-elite social classes (Salamandra 2004). New practices and urban identities were tied to these transformations, which gradually permeated the Sha'llan and Internet scenes with consumptive patterns relating to a global capitalist modernity that root queer practices to the consumption of the latest trends in fashion, music, and media. Men ascribe to the latest fashion trends, frequent European cafés and up-scale restaurants. These politics of class access and consumption were a distinguishing feature of these scenes: making consumption and class access a distinguishing marker of queer practices and subjectivities.

Global circulations of queer cultural forms have been put in tension with local conditions, creating a tense, shifting border between queer forms and practices deemed modern and progressive, and those that are "traditional," non-modern, and improper (Georgis 2013; Massad 2007). As anthropologist Evelyn Blackwood (2006) notes, the traditional/modern binary is produced in the circulation of Western sexual epistemologies in both effacing sexualities that do not correspond to modern same-sex identities of liberation movements in the West, and perpetuating the assumption that these individuals are left behind, marginalized, or in need of education to become liberated queer subjects. There is a complex interplay between colonial and globalizing forces and the adoption of elements into local socio-political fields (Povinellie \& Chauncey 1999). The internationalization of gay sexualities has been asymmetrical, with greater weight given to the force of Western-derived identities embodied in politics of liberal ideals of visibility, rights, and public sphere (Altman 1996; Massad 2007). The circulations of queer discourses about modernity and sexual freedom creates a "transnational queer discourse that ... is shaped by asymmetries of race, class, and gender, and reconstituted into particular subjectivities that do not fit neatly into Western-defined identities categories" (Blackwood 2008: 482). Resulting is a social field in a complexly intertwined mapping of spaces that are made distinct, by tensely interconnected qualities constituting a spatial-social structuring through the binary between tradition/modern. 


\section{Being Affected by New Scenes: Philip's Park Flirtation}

I turn now to the case of Philip to illustrate what happens when one is moved, both physically and mentally, among spaces. I first came to know Philip as Ali's friend in Sha'llan. Phillip-sensitive and often heartbrokenwas a staple in the Sha'llan scene, until he was ostracized from his social group, an affair he blamed on his lack of muscles and erotic capital. He desired a romantic relationship and emotional fulfillment but he could not find it among the men in Sha'llan. He usually refused my invitations to join me in the park and bar because he, like others, viewed these scenes as an undesirable queer place that is weak social bonds, quiet, furtive, and sexual (in contrast to others for whom the conditions serve the kind of quiet queer life they want to life). This was until I brought him one night.

We were chatting on a bench while a man looked over uninterruptedly. The man began walking the park's spiral path, starring at Phillip each time he passed. Phillip, enthralled by the attention, returned his glances. After a few rounds, he joined us, and they chatted, eventually exchanging numbers. "Wow, I never thought that would happen here" he said to me, a big smile on his face, feeling triumphant from the bit of positive attention. "Getting attention here was easier than in Sha'llan." His attachments to the Sha'llan scene were transformed by his own affective experience and the events of this social interactions, opening him to a new sense of queer selfhood in the park. Philip's shift from one scene to another, but also from one kind of social engagement to another, suggests a manner of affectation that disrupts the connections he had between a proper queer identity and the spaces one should thus inhabit. The act of flirting as movement of the body around the park opened Philip to an intimate possibility in a new scene.

Philip became a little different that night, perhaps both in a new sense of triumph where he was often despondent, but also in his sense of queer self. Philip's experience moved him (both affectively and physically from one urban space to another) in a way that he opened his queer subjecthood from being anchored within Sha'llan to a different form of queerness in the park. It was not that he was becoming something other than himself, but that the moment had disrupted the pattern of the Sha'llan scene, in which he was precariously caught. He had seen himself as one who was part of Sha'llan over other scenes, but was moved by crossing the social and affective border between Sha'llan and the Park scenes. The experience was an event of Deleuzian becoming: "an act of bordering in which ... categories are revealed to be infinitely other that what they are" (Dave 2014: 448). His queerness could be something different (even for the moment, but a moment can be a brief world) than that of the scene that rejected him. It could be wider; he could become something more.

\section{Movement and Queer Life}

As David Ruffolo (2009) writes of post-queer politics: "There is no single subject or fixed positionality in a critical politics of becoming because everything is creatively connected through the machines of life" (40). 
Queer life in Damascus was made from the density of interconnections of the ordinary moments generated as men move around queer scenes. The queer spaces that I have explored in Damascus combine into a complex differentiated, yet interconnecting, queer geography mapping practices, social relations, and subjectivities. Describing the qualities and characteristics of the scenes reveal how men positioned themselves within them, navigating among the similarities and differences between the scenes. Like the literature on movement, borders, spaces, and life (Ingold 2008; Stewart 2008; Merabet 2014), mobility and relations among borders shape queer bodies and subjectivities (in turn shaping spatial formations) as they exist in and among these various scenes.

Joining these queer scenes means crossing borders. And, as the examples have shown, either through Badik's disavowal, Ali's ease, and Philip's shift, crossing these borders means something, and can produce new things. The body takes a shape, adopts movements and gesticulations that are pantomime of the scene: from ostentatious gaits and bodily movements that pushed normative bodily codes, to the slow and steady walking in circles, the head nods, the glances, all those bodily forms that characterize certain scenes over others. The scenes are social worlds that affect those within, bringing out certain forms of queerness, and hold those awaiting conditions for the production and reproduction of queer life in the city. Movement is an effect of a personal interaction with external boundaries and meanings. 
Al-Samman, H., \& El-Ariss, T. (2013). "Queer Affects: Introduction." International Journal of Middle East Studies, 45(2): 205-209.

Altman, D. (1996). "Rupture or Continuity? The Internationalization of Gay Identities." Social Text (48): 7794.

Amar, P. (2013). The Security Archipelago: Human-Security States, Sexuality Politics, and the End of Neoliberalism. Duke University Press.

Babayan, K., \& Najmabadi, A. (eds.). (2008). Islamicate Sexualities: Translations across Temporal Geographies of Desire. Harvard Center for Middle Eastern Studies.

Bell, D. \& Valentine, G. (eds.). (1995). Mapping Desire: Geographies of Sexualities. London: Routledge.

Benedicto, B. (2014). Under Bright Lights: Gay Manila and the Global Scene. University of Minnesota Press.

Bingham, N., \& Thrift, N. (2000). "Some New Instructions for Travelers: The Geography of Bruno Latour and Michel Serres." In Thinking Space, M. Crang \& N. Thrift (eds.). Routledge.

Binnie, J. (1997). "Coming Out of Geography: Towards a Queer Epistemology?" Environment and Planning D: Society and Space 15: 223-37.

Blackwood, E. (2008). "Transnational Discourses and Circuits of Queer Knowledge in Indonesia." GLQ: A Journal of Lesbian and Gay Studies, 14(4): 481-507.

Boellstorff, T. (2005). The Gay Archipelago: Sexuality and Nation in Indonesia. Princeton University Press.

Bouhdiba, A. (2001). Sexuality in Islam. London: Saqi Books.

Brennan, T. (2004). The transmission of affect. Cornell University Press.

Butler, J. (1993). Bodies that Matter: On the Discursive Limits of Sex. New York: Routledge.

Butterfield, N. (2016). "Professionalization in Sexual Politics and Activism in Croatia in the 2000s." Southeastern Europe, 40: 54-80.

Dave, N. (2014). "Witness: Humans, Animals, and the Politics of Becoming." Cultural Anthropology, 29(3): 433-456.

Davies, A.M. (2013). "(Un)stable Space(s): an Ethnography of a (sometimes) Gay Bar." The Qualitative Report 18(16): 1-14.

de Certeau, M. (1984). The Practice of Everyday Life. University of California Press.

El-Rouayheb, K. (2009). Before Homosexuality in the Arab-Islamic world, 1500-1800. Chicago: University of Chicago Press.

Georgis, D. (2013). "Thinking Past Pride: Queer Arab Shame in Bareed Mista3jil." International Journal of Middle East Studies 45(02): 233-251.

Habib, S. (2007). Female Homosexuality in the Middle East: Histories and Representations. Routledge.

--. (2009). Islam and Homosexuality. Praeger.

Hamdan, S. (2015). "Re-orienting Desire from with/in Queer Arab Shame: Conceptualizing Queer Arab Subjectivities through Sexual Difference Theory in a Reading of Bareed Mista3jil." Kohl: a Journal for Gender and Body Research, 1(1): 55-69.

Haraway, D. (1988). "Situated knowledges: the science question in feminism and the privilege of partial perspective." Feminist Studies, 14(3): 575-599. 
Ingold, T. (2008). "Bindings against Boundaries: Entanglements of Life in an Open World." Environment and Planning A, 40: 1798-1810.

Ingram, G.B., Bouthillette, A.M., \& Retter, Y. (eds.). (1997). Queers in Space: Communities, Public Places, Sites of Resistance. Seattle: Bay Press.

Joseph, S. (2010). "Gender and citizenship in the Arab world." Al Raida, (129-130): 8-18.

MacDonald, G. (1992). "Among Syrian Men." In Sexuality and Eroticism among Males in Moslem Societies, A. Schmitt \& J. Sofer (eds.). Routledge.

Madison, D.S. (2005). Critical Ethnography: Method, Ethics, and Performance. Thousand Oaks, CA: Sage. Maktabi, R. (2010). "Gender, Family Law and Citizenship in Syria." Citizenship Studies, 14(5): 557-572.

Markowitz, L., \& Tice, K.W. (2002). "Paradoxes of Professionalization: Parallel Dilemmas in Women's Organizations in the Americas." Gender \& Society, 16(6): 941-958.

Massad, J. (2007). Desiring Arabs. Chicago: University of Chicago Press.

Merabet, S. (2014). Queer Beirut. Austin: University of Texas Press.

McCormick, J. (2006). "Transition Beirut: Gay identities, Lived Realities." In Sexuality in the Arab world, S. Khalaf (ed.). Saqi Books.

McGlotten, S. (2005). Queerspaces and Sexpublics: Desire, Death, and Transfiguration. Dissertation: University of Texas, Austin.

Mourad, S. (2013). "Queering the Mother Tongue." International Journal of Communication, 7: 2533-2546.

Moussawi, G. (2015). "(Un)critically Queer Organizing: Towards a More Complex Analysis of LGBTQ Organizing in Lebanon." Sexualities, 1-25.

Munt, S. (2002). "Lesbian Flâneur." In The Unknown City: Contesting Architecture and Social Space, I. Borden, J. Kerr \& A. Pivaro (eds.). MIT Press.

Navaro-Yashin, Y. (2012) The Make-Believe Space: Affective Geography in a Postwar Polity. Duke University Press.

Pace, S. (2012). "Writing the Self into Research: Using Grounded Theory Analytic Strategies in Autoethnography." TEXT Journal of Writing and Writing Courses, 16(1): 1-15.

Povinelli, E. A., \& Chauncey, G. (1999). "Thinking Sexuality Transnationally." GLQ: A Journal of Lesbian and Gay Studies, 5(4): 439-450.

Pullen, C. (2012). "LGBT Transnational Documentary 'Becoming." In LGBT Transnational Identity and the Media, C. Pullen (ed.). Palgrave Macmillian.

Qubaia, Adrianna. Forthcoming. "Imagining Non-Normative Sexualities in Beirut." Dissertation. Central European University.

Ruffolo, D.V. (2009). Post-Queer Politics. Ashgate.

Salamandra, C. (2004). A New Old Damascus: Authenticity and Distinction in Urban Syria. Indiana: Indiana University Press.

Salter, M. B. (2012). "Theory of the l: The Suture and Critical Border Studies." Geopolitics 17(4): 734-755.

Seidman, S. (2012). "The Politics of Cosmopolitan Beirut: From the Stranger to the Other. Theory, Culture \& Society, 29(2): 3-36.

Sibalis, M. (2004). "Urban Space and Homosexuality: The Example of the Marais, Paris' 'Gay Ghetto." Urban Studies 41(9): 1739-1758. 
Skeggs, B., Moran, L., Tyrer, P. \& Binnie, J. (2004). "Queer as Folk: Producing the Real of Urban Space." Urban Studies 41(9): 1839-1856.

Stewart, K. (2008). "Weak Theory in an Unfinished World." Journal of Folklore Research 45(1): 71-82.

Straw, W. (2004). "Cultural Scenes." Society and Leisure 27(2): 411-422.

Thrift, N. (2007). Non-Representational Theory: Space, Politics, Affect. New York: Routledge.

Valentine, G. (2002). "Queer Bodies and the Production of Space." In Handbook of Lesbian and Gay Studies, D. Richardson \& S. Seidman (eds.). Thousand Oaks, CA: Sage.

Vannini, P. (2015). "Non-Representational Research Methodologies: an Introduction." In NonRepresentational Research Methodologies: Re-Envisioning Research, P. Vannini (ed.). Routledge.

Vaughan-Williams, N., Parker, N., et al. (2009). "Lines in the Sand? Towards an Agenda for Critical Border Studies." Geopolitics, 14(3): 582-587.

Wehbi, S. \& El-Lahib, Y. (2007). "Organising for Voting Rights of People with Disabilities in Lebanon: Reflections for Activists." Equal Opportunities International, 26(5): 449-464.

Whatmore, S. (2002). Hybrid Geographies: Natures Cultures Spaces. Sage Publications.

Zaki, M.A. (2014). "And they say there aren't any gay Arabs...:" Ambiguity and Uncertainty in Cairo's Underground Gay Scenes. PhD Dissertation: London School of Economics and Political Science. 